\title{
DESIGN THINKING COMO ESTRATÉGIA DE INOVAÇÃO EM BIBLIOTECAS
}

\section{DESIGN THINKING COMO ESTRATEGIA DE INNOVACIÓN EN LAS BIBLIOTECAS}

\author{
Jordan Paulesky Juliani* \\ Diego de Castro Vieira** \\ Déborah Medeiros*** \\ Douglas Paulesky Juliani****
}

\begin{abstract}
RESUMO:
Introdução: A necessidade por inovar e caracterizar o que é novo, faz com que o termo inovação esteja permanentemente na agenda de um número crescente de organizações dos mais variados segmentos. As bibliotecas enquanto organizações precisam inovar, trata-se de uma demanda emergente.

Objetivo: Empregar as técnicas e processos do design thinking (DT) como instrumento de inovação na Biblioteca Universitária da UDESC.

Metodologia: Trata-se de uma pesquisa qualitativa, desenvolvida por meio de uma pesquisa-ação. Os dados foram coletados por meio de entrevistas. Concluída a coleta de dados realizaram-se as etapas do DT, a partir do emprego da técnica do grupo focal.

Resultados: O processo de DT permitiu desenvolver uma inovação incremental para a Biblioteca. Para que a inovação aconteça é fundamental que os atores envolvidos no processo estejam libertos de paradigmas e ideias preconcebidas. A utilização das técnicas de grupo focal, combinada com a de cartões de insights e diagrama de afinidades foram fundamentais para que as etapas do DT pudessem ter sido

*Doutor em Engenharia e Gestão do Conhecimento. Professor do Departamento de Biblioteconomia e Gestão da Informação (BDI) da UDESC. Docente permanente do Programa de Pós-Graduação em Gestão da Informação na mesma instituição. E-mail jordanjuliani@gmail.com

**Mestre em Gestão da Informação pelo Programa de Pós-graduação em Gestão da Informação - UDESC. E-mail monitordiego@gmail.com

***Mestre em Gestão da Informação pelo Programa de Pós-graduação em Gestão da Informação - UDESC. E-mail binhaa.medeiros@gmail.com

**** Doutor em Engenharia e Gestão do Conhecimento. Professor do Instituto Federal de Santa Catarina - IFSC. E-mail douglasjuliani@ifsc.edu.br
\end{abstract}


realizadas com sucesso.

Conclusões: A prototipação da inovação na biblioteca da UDESC sugeriu uma melhora significativa ao uso da sua estrutura e recursos disponíveis. O DT demonstrou-se simples e efetivo para sistematizar a inovação em bibliotecas.

Palavras-chave: Inovação. Bibliotecas universitárias.

\section{INTRODUÇÃO}

Os recentes avanços tecnológicos, a competição global, a necessidade por inovar e caracterizar o que é novo, fazem com que o termo "inovação" esteja permanentemente na agenda de um número crescente de organizações dos mais variados segmentos. A inovação passou a ser uma aliada nas práticas dessas organizações por possibilitar a geração de diferenciais competitivos para sobrevivência em um mercado altamente acirrado.

Colocar em prática a inovação não é uma tarefa simples. Exige das organizações práticas sistematizadas, por meio de processos organizacionais formalizados e integrados ao sistema de gestão (TERRA, 2007). Além disso, a organização precisa criar um ambiente propício para geração de ideias e estímulo a criatividade, com a presença de lideranças que incentivem a adoção de atitudes inovadoras pelos times de trabalho. Jungmann e Bonetti (2010) reforçam que para uma organização ser inovadora é fundamental que exista sinergia entre as lideranças e integrantes da equipe, visando à complementaridade e à convergência de esforços para prover recursos e conhecimentos para o desenvolvimento de soluções inovadoras.

Uma das práticas adotadas pelas organizações para soluções de problemas complexos de maneira colaborativa e aprendizados constantes é o Design Thinking. O Design Thinking "[...] se refere à maneira do designer de pensar [...]", ou seja, é um processo multifásico e não linear, do qual as organizações não estão habituadas (VIANNA et al., 2014, p. 13). As organizações que adotam o processo de Design Thinking se sobressaem em relação à concorrência, pois estão continuamente redesenhando seus modelos de negócios visando avançar no processo de inovação e eficiência como 
vantagem competitiva (MARTIN, 2010).

Como forma de aplicar o processo de Design Thinking em busca de soluções inovadoras, neste trabalho, utilizou-se de suas etapas para o desenvolvimento de uma proposta de inovação voltada para a melhoria nos serviços e produtos da Biblioteca Universitária da Universidade do Estado de Santa Catarina - UDESC. Após a aplicação das etapas do Design Thinking: Imersão, Análise e Síntese, e Ideação, obteve-se como resultado a proposta de inovação na sinalização da biblioteca universitária, identificada pelos participantes da pesquisa. Uma vez finalizada a etapa de ideação, realizou-se a prototipação da sinalização da Biblioteca da UDESC.

Para o desenvolvimento desta pesquisa, foram levantados os principais conceitos e tipos de inovação, além da descrição do Design Thinking e suas etapas, o que permitiu obter uma visão holística sobre a temática. Esse panorama teórico sobre inovação foi fundamental na condução da pesquisa, principalmente por explicitar as principais técnicas aplicadas na condução do processo de Design Thinking. Vale destacar que estas etapas não precisam ser aplicadas de maneira linear, como são apresentadas neste trabalho, pois possuem uma natureza proeminentemente flexível e adaptável a cada realidade.

\section{O CONTEXTO DA INOVAÇÃO}

No contexto organizacional o termo inovação é utilizado para apresentar, de forma genérica, necessidades de melhoria e de concepção do "novo" - de processos, de produtos, de formas de gestão, de posicionamento estratégico e da aplicação dessas melhorias e concepções de maneira a obter vantagem competitiva sobre seus concorrentes. Essas vantagens podem ser desdobradas em redução de custos, maior flexibilidade e agilidade, menor concorrência, ou seja, cria-se um ambiente propício para competição (DESCHAMPS; HERMANN, 2011).

Terra (2007) destaca que tradicionalmente, no âmbito organizacional, associa-se inovação ao desenvolvimento de produtos ou avanços tecnológicos. 
Entretanto, o autor apresenta uma perspectiva mais moderna dessa concepção, por meio da compreensão da inovação em outras dimensões, como em processos, relacionamento com clientes, serviços, relacionamento com as partes interessadas, entre outras. Portanto é preciso visualizar a inovação de forma sistêmica, em vez de se limitar aos processos de Pesquisa \& Desenvolvimento (P\&D). A inovação necessita de boas ideias, e sobretudo demonstrar resultados que possam ser tangibilizados.

Esses resultados são oriundos da capacidade da organização de transformar ideias, ponto de partida, em valor, agregando tecnologias e oferecendo produtos que atendam as necessidades do mercado, sendo fonte de renda e empregos (JUNGMANN; BONETTI, 2010). Nesse sentido, a inovação se configura como um tema permanente e estratégico para as organizações, contribuindo para o fortalecimento da competitividade de um país.

A inovação desempenha um papel central na economia baseada no conhecimento, pois possibilita um crescimento sustentado e inclusivo, não apenas do ponto de vista tecnológico, mas socioeconômico. Segundo a Organização para Cooperação Econômica e Desenvolvimento - OCDE (2005), por meio do Manual de Oslo, principal referência sobre inovação no mundo, existem duas formas de analisar a inovação no contexto da sociedade do conhecimento. No nível macro, há fortes evidências de que a inovação é o fator dominante no crescimento econômico nacional e nos padrões do comércio internacional. Já no nível micro, um olhar para as organizações, a P\&D é vista como o fator de maior capacidade de absorção e utilização de novos conhecimentos dos mais variados tipos, não apenas tecnológico.

De maneira geral, a inovação possui duas dimensões: uma estratégica e outra operacional. A primeira dimensão está voltada para aspectos que promovem o estabelecimento de uma cultura de inovação na organização e a forma como a inovação pode afetar os resultados nos negócios. Na segunda dimensão, o cerne é a preocupação com práticas bem-sucedidas que possam catalisar o processo de inovação no dia a dia da organização - não apenas para inovações com um conteúdo tecnológico significativo ou mesmo 
revolucionário, mas também para inovações que são um rearranjo do que já é conhecido, fornecendo uma nova forma de encarar o negócio ou uma nova forma de executar os processos, por exemplo, com ganhos que possam ser colhidos também no curto prazo.

Por isso, a competência de inovar por parte das organizações ganha notoriedade na medida em que suas práticas lhe permitam prosperar de maneira sustentável ou esmorecer.

\subsection{Desmistificando a inovação}

A inovação está no radar do gerenciamento das organizações desde os anos 50, quando Peter Drucker destacou a relação da capacidade de inovar com o sucesso competitivo (ARAÚJO; GAVA, 2011). Independente das condições em que a organização está inserida, a chave para se criar e manter vantagem competitiva tende a pertencer àquelas organizações que inovam continuamente (TIDD; BESSANT; PAVITT, 2008).

Décadas após o posicionamento de Drucker, ainda se percebe sua atualidade, pois a palavra inovação está presente nas diretrizes das organizações e no discurso de grande parte dos executivos, reforçando que a inovação é fundamental para o crescimento no longo prazo e a prosperidade dos negócios (GIBSON; SKARZYNSKI, 2008). Por outro lado, esse reconhecimento e relevância protagonizados pela inovação também conduziu ao tema uma série de distorções e confusões acerca do que se fala e pensa sobre o processo de inovação, por isso a importância de desmitificar os conceitos relacionados a esse termo tão usual, mas ao mesmo tempo distante, no contexto das organizações.

Para tanto, faz-se necessário compreender as diferenças entre inovação, descoberta científica e invenção. Segundo a Financiadora de Estudos e Projetos - FINEP (2006), invenção é a criação de algo novo, resultado do esforço humano. A descoberta científica está relacionada a algo que já existia, mas sem impacto para a sociedade. Já a inovação é decorrente da aplicação prática para uma descoberta ou invenção.

Em outras palavras, pode-se dizer que existe uma relação muito tênue entre o conceito de invenção e inovação. A invenção pressupõe a concepção 
de uma nova ideia, que pode estar ligada a pesquisa, tecnologia ou até mesmo ao mundo artístico. É a aplicação de um conjunto de conhecimentos sistematizados ou não. Por outro lado, a inovação requer uma aplicação prática dessa ideia, ou seja, o mercado precisa perceber valor.

Etimologicamente, a palavra inovar deriva do latim in+inovare, que significa "fazer novo", modificar ou renovar. De maneira simples, inovação denota ter uma nova ideia ou, também, aplicar as ideias de outras pessoas em novidades ou de uma forma nova (TERRA, 2007).

Um dos principais conceitos apresentado na literatura sobre inovação é de autoria de Schumpeter (1997), pois o autor baseou-se em diferentes fatores geradores de inovações que interferem no desenvolvimento econômico da sociedade. Portanto, inovação, para o autor, contempla cinco fatores:

1) Introdução de um bem no mercado que os consumidores não conhecem;

2) Introdução de um método de produção que tenha sido gerado a partir de uma nova descoberta científica ou de um novo método de tratar comercialmente uma commodity;

3) Abertura de um novo mercado em que uma área específica da organização não esteja presente, independente de o mercado já existir;

4) Conquista de uma nova fonte de suprimentos de matéria-prima ou de bens parcialmente manufaturados; ou

5) Aparecimento de uma nova estrutura organizacional que possa ser aplicada em um determinado setor.

É importante destacar, no conceito de Schumpeter (1997), três aspectos estruturais: a novidade, ou seja, a ideia de que uma inovação é o aparecimento de algo novo, ainda não usado ou explorado; a aplicação prática, isto é, esse algo novo precisa ser aplicado em uma atividade econômica; e, por fim, o resultado, que é a aplicação bem sucedida de uma invenção, podendo ser de ordem financeira, econômica ou organizacional. 
Por sua vez, o Manual de Oslo apresenta o seguinte conceito para inovação:

\begin{abstract}
Uma inovação é a implementação de um produto (bem ou serviço) novo ou significativamente melhorado, ou um processo, ou um novo método de marketing, ou um novo método organizacional nas práticas de negócios, na organização do local de trabalho ou nas relações externas (OCDE, 2005, p.46):
\end{abstract}

A partir dos conceitos de inovação apresentados, pode-se dimensionar sua complexidade, muitas vezes difícil de imaginar. Apesar de a inovação envolver variáveis complexas, a única maneira de compreendê-la de fato, é aprendendo a inovar. Infelizmente algumas organizações, por conveniência, utilizam modelos de inovação formatados que não se enquadram no seu perfil, gerando resultados frustrantes e perdendo a oportunidade de vivenciar a inovação no seu contexto.

\title{
2.1.1 Tipos de inovação
}

Ao longo dos anos, os conceitos de inovação sofreram evoluções tanto na compreensão do que é inovar quanto nos atores que podem fazer parte do processo. A inovação deixa de ser vista essencialmente pela tecnologia, mas também sob outros prismas, como produção, comercialização dos produtos, gestão, entre outros (FINEP, 2006).

Assim como existem múltiplas definições sobre inovação, o mesmo ocorre com a grande variedade de tipos ou classificação de inovação apresentados pela literatura especializada. Entretanto, as inovações são usualmente classificadas de duas maneiras distintas. A primeira leva em consideração objeto em foco - no que a inovação ocorre. Já a segunda leva em consideração o grau em que a inovação ocorre.

No que se refere à forma como a inovação acontece, recorre-se ao Manual de Oslo, que define quatro tipos de inovação que geram impacto nas diversas atividades da organização: inovações de produto, de processos, organizacionais e de marketing, conforme demonstrado no quadro 1 a seguir (OCDE, 2005). 
Jordan Paulesky Juliani, Diego de Castro Vieira, Déborah Medeiros, Douglas Paulesky Juliani.

Design thinking como estratégia de inovação em bibliotecas

Quadro 1 - Tipos de inovação

\begin{tabular}{|l|l|}
\hline Tipo de Inovação & \multicolumn{1}{|c|}{ Definição } \\
\hline $\begin{array}{l}\text { Inovações em } \\
\text { produto }\end{array}$ & $\begin{array}{l}\text { Introdução de um benefício ou serviço novo ou melhorado, em relação } \\
\text { às suas características ou usos pretendidos. Podem ser melhorias nas } \\
\text { especificações técnicas, componentes e materiais, software, interface } \\
\text { com usuário ou outras características funcionais. }\end{array}$ \\
\hline $\begin{array}{l}\text { Inovações em } \\
\text { processo }\end{array}$ & $\begin{array}{l}\text { Refere-se à implementação de processo produtivo ou distribuição, novos } \\
\text { ou significativamente melhorados. Isto inclui modificações significativas } \\
\text { em técnicas, equipamentos e/ou software. }\end{array}$ \\
\hline $\begin{array}{l}\text { Inovações } \\
\text { organizacionais }\end{array}$ & $\begin{array}{l}\text { Implementação de novos métodos organizacionais, podendo ser } \\
\text { mudanças em práticas de negócio, na organização do ambiente de } \\
\text { trabalho, ou nas relações externas da empresa. }\end{array}$ \\
\hline $\begin{array}{l}\text { Inovações em } \\
\text { marketing }\end{array}$ & $\begin{array}{l}\text { Implementação de novos métodos de marketing. Podem ocorrer } \\
\text { mudanças na aparência do produto e sua embalagem, na divulgação e } \\
\text { distribuição dos produtos e em métodos para definir preços de } \\
\text { benefícios e serviços. }\end{array}$ \\
\hline
\end{tabular}

Fonte: Adaptado de OCDE (2005).

As inovações de produto ou serviço, de processo e em gestão, estão usualmente vinculadas à geração de ideias e ao seu desenvolvimento por meio de atividades sistematizadas, como a pesquisa aplicada ou o desenvolvimento experimental.

A segunda maneira de classificar as inovações, descrita por Freeman e Perez (1988), leva em consideração o grau em que a inovação ocorre. Segundo essa forma de classificação uma inovação pode ser:

$\checkmark \quad$ Radical: é o surgimento de um novo produto, serviço, processo, negócio ou de uma nova forma de gestão significativamente diferente dos já existentes e que possibilite a criação de novos negócios ou novos mercados;

$\checkmark$ Incremental: é a melhoria em um produto, serviço, processo, negócio ou uma forma de gestão já existente de maneira a aprimorar ou expandir a sua aplicabilidade.

De acordo com Coral, Ogliari e Abreu (2008) a inovação radical é fortemente baseada na pesquisa científica e tecnológica, por meio de projetos com significativo risco e investimento com foco no longo prazo. Já as inovações incrementais são consideradas mais seguras, econômicas e trazem resultado 
no curto prazo, pois geralmente são realizadas dentro da organização.

Outra forma de classificar inovação é apresentada pelo professor Clayton Christensen (2003), da Escola de Negócios da Universidade de Harvard, Boston, EUA, em seu livro The innovator's dilemma, que categoriza as inovações de acordo com a sua capacidade de sustentar ou romper com paradigmas anteriormente concebidos. A partir deste entendimento as inovações podem ser sustentativas ou disruptivas. A inovação sustentativa é representada pela melhoria do desempenho de um produto já existente de forma a sustentá-lo no mercado. Pode ser incremental ou radical, conforme a classificação anterior. A inovação disruptiva é baseada em uma nova proposição de valor sobre um produto existente. Essa proposição de valor pode, por exemplo, diminuir o desempenho e melhorar o custo da organização ou vice-versa.

\subsection{Instrumento para inovação: Design Thinking}

O Design Thinking apresenta-se como um instrumento para desenvolver a inovação nos mais diversos contextos e negócios. O Design Thinking é considerado "[...] uma abordagem focada no ser humano que vê na multidisciplinaridade, colaboração e tangibilização de pensamentos e processos, caminhos que levam a soluções inovadoras para negócios" (VIANNA et al., 2014, p. 12).

O termo Design Thinking surgiu por meio do estudo "Wicked Problems in Design Thinking" de Richard Buchanan, publicado em 1992, que altera o conceito tradicional do design extrapolando a sua atuação na produção industrial. A partir desse estudo, o conceito de design foi ampliado para Design Thinking, com uma abordagem voltada para a elaboração e solução de problemas e geração de valor por meio do reconhecimento dos aspectos sociais do trabalho de Design (BIOLCHINI; PIMENTA; OROFINO, 2012).

Uma rápida tradução do termo Desing Thinking seria pensar como um designer pensaria, representando a forma como os designers abordam a resolução de problemas (BROWN, 2010). Vale destacar que o designer utiliza um tipo de raciocínio pouco utilizado no mundo corporativo: o pensamento 
abdutivo, a solução não é derivada do problema, ela se encaixa nele (VIANNA et al., 2014).

Sendo assim, como todo processo de inovação, o Design Thinking coloca-se como uma ferramenta de criação do conhecimento tendo em vista que pode ser um aliado na resolução de problemas complexos, e um agente de mudança que possibilita a compreensão dos desafios atuais (OROFINO, 2011). Para uma melhor compreensão dos processos e métodos utilizados pelo Design Thinking a fim de facilitar a sua aplicação prática em problemas complexos, Vianna et al. (2014) apresentam as etapas do processo de Design Thinking, conforme destacado na figura 1.

Figura 1 - Etapas do processo de Design Thinking

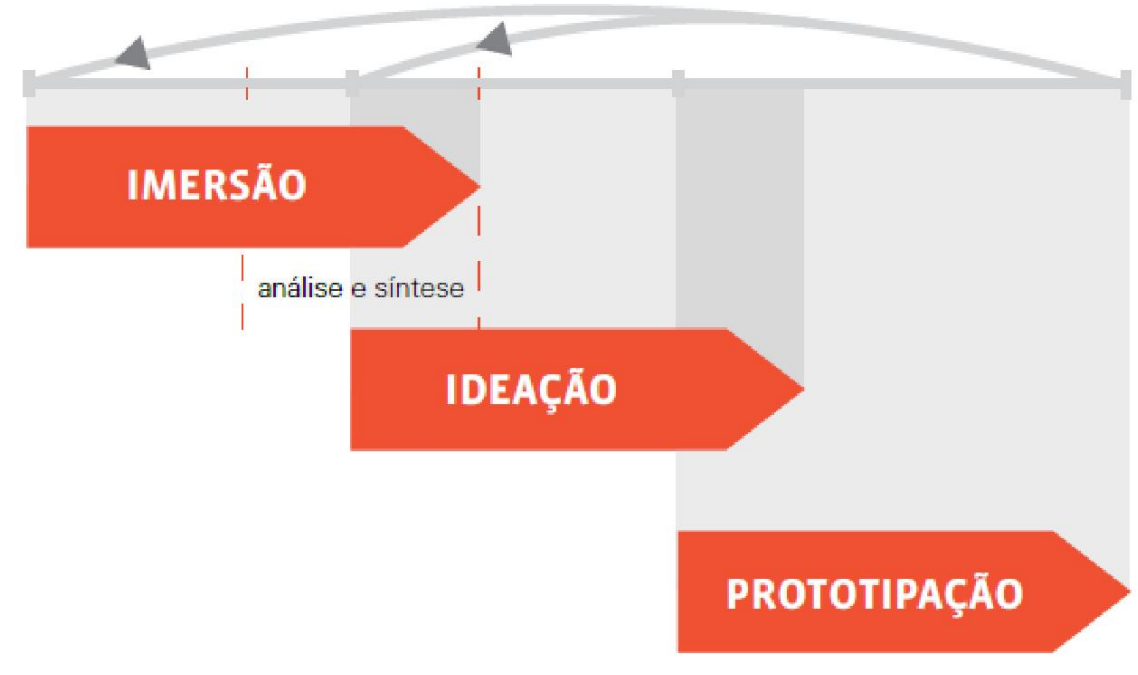

Fonte: Vianna et al. (2014, p. 18).

A primeira etapa do processo de Design Thinking é chamada de Imersão e tem a finalidade de aproximação do contexto do problema por parte da equipe do projeto. Essa fase é ainda subdividida em Imersão Preliminar e Imersão em Profundidade. A imersão preliminar visa uma compreensão inicial do problema e, caso necessário, seu reenquadramento. Já a imersão em profundidade busca identificar as necessidades dos atores envolvidos no projeto e as oportunidades que emergem frente ao tema trabalhado. Como 
Jordan Paulesky Juliani, Diego de Castro Vieira, Déborah Medeiros, Douglas Paulesky Juliani.

Design thinking como estratégia de inovação em bibliotecas

saída dessa etapa tem-se um grande volume de informações que precisam ser tratadas na segunda etapa de Análise e Síntese, a fim de organizar visualmente esses dados, identificando oportunidades e desafios (VIANNA et al., 2014).

O intuito da terceira fase, denominada de Ideação, é gerar ideias inovadoras para o tema do projeto por meio de atividades colaborativas que estimulem a criatividade. Para isso, utilizam-se as ferramentas de síntese criadas na fase de análise para estimular a criatividade e gerar soluções de acordo com o contexto do projeto (VIANNA et al., 2014).

Por fim, a última etapa refere-se à prototipação, que tem como objetivo validar e tangibilizar as ideias geradas. Apesar dessa etapa ser apresentada ao final do processo de Design Thinking, pode ocorrer ao longo do projeto em paralelo com a imersão e ideação (VIANNA et al., 2014).

Para cada etapa do processo de Design Thinking são utilizadas diferentes técnicas de acordo com a necessidade apresentada para a busca da solução. Nesse sentido, buscou-se destacar no quadro 2 as principais técnicas e suas descrições para cada etapa do processo.

Quadro 2 - Principais técnicas utilizadas no Design Thinking

\begin{tabular}{|l|l|l|}
\hline \multicolumn{1}{|c|}{ Etapa } & \multicolumn{1}{|c|}{ Técnicas } & \multicolumn{1}{|c|}{ Descrição } \\
\hline \multirow{4}{*}{$\begin{array}{l}\text { Imersão } \\
\text { Preliminar }\end{array}$} & Reenquadramento & $\begin{array}{l}\text { Reunião com a equipe do projeto para analisar o } \\
\text { problema sob outras perspectivas e definir as } \\
\text { fronteiros do projeto. }\end{array}$ \\
\cline { 2 - 3 } & Pesquisa exploratória & $\begin{array}{l}\text { Pesquisa de campo preliminar para compreensão do } \\
\text { contexto a ser trabalhado. }\end{array}$ \\
\cline { 2 - 3 } & Pesquisa Desk & $\begin{array}{l}\text { Busca de informações sobre o tema do projeto em } \\
\text { diversas fontes. }\end{array}$ \\
\hline \multirow{3}{*}{$\begin{array}{l}\text { Imersão em } \\
\text { Profundidade }\end{array}$} & $\begin{array}{l}\text { Entrevistas } \\
\text { Sensibilização }\end{array}$ & $\begin{array}{l}\text { Procura obter informações por meio de perguntas, } \\
\text { cartões de evocação cultural, dentre outras técnicas. }\end{array}$ \\
\cline { 2 - 3 } & $\begin{array}{l}\text { Cadernos de } \\
\text { mínimo de interferência sobre suas ações, ou quando } \\
\text { a questão investigada ocorre num longo período de } \\
\text { tempo. }\end{array}$ \\
\cline { 2 - 3 } & Sessões generativas & Encontro com os atores envolvidos no projeto para \\
\hline
\end{tabular}

Inf. Inf., Londrina, v. 21, n. 3, p. 101 - 123, set./dez., 2016. 
Jordan Paulesky Juliani, Diego de Castro Vieira, Déborah Medeiros, Douglas Paulesky Juliani.

Design thinking como estratégia de inovação em bibliotecas

\begin{tabular}{|c|c|c|}
\hline & & $\begin{array}{l}\text { que dividam suas experiências e visões sobre o tema } \\
\text { do projeto. }\end{array}$ \\
\hline & Um dia na vida & $\begin{array}{l}\text { Simulação, por parte do pesquisador, da vida de uma } \\
\text { pessoa ou situação estudada. }\end{array}$ \\
\hline & Sombra & $\begin{array}{l}\text { Acompanhamento do usuário ao longo de um período } \\
\text { de tempo que inclua sua interação com o produto ou } \\
\text { serviço que está sendo analisado. }\end{array}$ \\
\hline & Cartões de insights & $\begin{array}{l}\text { Reflexões embasadas em dados reais das pesquisas, } \\
\text { transformados em cartões que facilitam a rápida } \\
\text { consulta e o seu manuseio. }\end{array}$ \\
\hline & $\begin{array}{l}\text { Diagrama de } \\
\text { afinidades }\end{array}$ & $\begin{array}{l}\text { Organização e agrupamento dos cartões de insights } \\
\text { com base em afinidade, similaridade, dependência ou } \\
\text { proximidade. }\end{array}$ \\
\hline & Mapa conceitual & $\begin{array}{l}\text { Visualização gráfica construída para simplificar e } \\
\text { organizar os dados, em diferentes níveis de } \\
\text { profundidade e abstração. }\end{array}$ \\
\hline & Critérios norteadores & $\begin{array}{l}\text { Diretrizes balizadoras para o projeto que não devem } \\
\text { ser perdidos de vista ao longo das etapas do } \\
\text { desenvolvimento das soluções. }\end{array}$ \\
\hline Análise e Síntese & Personas & $\begin{array}{l}\text { Personagens ficcionais, concebidos a partir da } \\
\text { síntese de comportamentos observados entre } \\
\text { consumidores com perfis extremos. }\end{array}$ \\
\hline & Mapa de empatia & $\begin{array}{l}\text { Ferramenta de síntese das informações sobre o } \\
\text { cliente numa visualização do que ele diz, faz, pensa e } \\
\text { sente. }\end{array}$ \\
\hline & Jornada do usuário & $\begin{array}{l}\text { Representação gráfica das etapas de relacionamento } \\
\text { do cliente com um produto ou serviço, descrevendo } \\
\text { os passos-chave percorridos durante o processo da } \\
\text { compra. }\end{array}$ \\
\hline & Blueprint & $\begin{array}{l}\text { Matriz esquemática e simples que representa o } \\
\text { complexo sistema de interações de uma prestação de } \\
\text { serviços. }\end{array}$ \\
\hline & Brainstorming & $\begin{array}{l}\text { Técnica para estimular a geração de um grande } \\
\text { número de ideias em um curto espaço de tempo. }\end{array}$ \\
\hline Ideação & $\begin{array}{l}\text { Workshop de } \\
\text { cocriação }\end{array}$ & $\begin{array}{l}\text { Encontro organizado na forma de uma série de } \\
\text { atividades em grupo com o objetivo de fomentar a } \\
\text { criação de soluções inovadoras. }\end{array}$ \\
\hline & Cardápio de ideias & $\begin{array}{l}\text { Catálogo apresentando a síntese de todas as ideias } \\
\text { geradas no projeto. }\end{array}$ \\
\hline
\end{tabular}

Inf. Inf., Londrina, v. 21, n. 3, p. 101 - 123, set./dez., 2016.

www.uel.br/revistas/informacao/ 
Jordan Paulesky Juliani, Diego de Castro Vieira, Déborah Medeiros, Douglas Paulesky Juliani.

Design thinking como estratégia de inovação em bibliotecas

\begin{tabular}{|l|l|l|}
\hline \multirow{5}{*}{ Prototipação } & $\begin{array}{l}\text { Matriz de } \\
\text { posicionamento }\end{array}$ & $\begin{array}{l}\text { Ferramenta de análise estratégica das ideias } \\
\text { geradas, utilizada na validação destas em relação } \\
\text { aos critérios norteadores. }\end{array}$ \\
\hline & Protótipo em papel & $\begin{array}{l}\text { Representações de interfaces gráficas com diferentes } \\
\text { níveis de fidelidade. }\end{array}$ \\
\cline { 2 - 3 } & Encenação & $\begin{array}{l}\text { Representações de um produto que pode variar os } \\
\text { níveis de fidelidade. }\end{array}$ \\
\cline { 2 - 3 } & Storyboard & $\begin{array}{l}\text { Simulação improvisada de uma situação. } \\
\text { Sepresentação visual de uma história por meio de } \\
\text { quadros estáticos. }\end{array}$ \\
\cline { 2 - 3 } & Protótipo de serviços & $\begin{array}{l}\text { Simulação de artefatos materiais, ambientes ou } \\
\text { relações interpessoais que representam um ou mais } \\
\text { aspectos de um serviço. }\end{array}$ \\
\hline
\end{tabular}

Fonte: Adaptado de Vianna et al. (2014).

É importante destacar que, por se tratar de um processo criativo, as etapas sugeridas para aplicação do Design Thinking podem sofrer alterações de acordo com a necessidade do projeto e da equipe. Apesar das etapas terem sido apresentadas de maneira linear, possuem uma natureza flexível, assim como todo processo criativo. A forma linear de apresentação não pode tornarse um fator inibidor da criatividade, pois o princípio básico do design thinking é a modelagem livre das ideias.

\section{METODOLOGIA}

O estudo caracteriza-se como uma pesquisa-ação devido a participação direta dos envolvidos na pesquisa com a solução do problema. Thiollent (1997) esclarece que o foco da pesquisa-ação é diagnosticar problemas e buscar soluções à organização, com caráter interrogativo-crítico. O pesquisador deve conduzir os atores a formular perguntas acerca da situação em que vivem no ambiente de trabalho, promovendo ampla interação entre pesquisadores e membros representativos da situação investigada.

No que se refere à natureza das variáveis pesquisadas, caracteriza-se por ser uma pesquisa qualitativa.

A coleta de dados envolveu alunos, professores, servidores da UDESC, 
empresários e a comunidade do bairro Itacorubi localizada nas proximidades da biblioteca. Os participantes foram questionados a partir da técnica de entrevista sobre as suas maiores dificuldades quanto ao uso da biblioteca da UDESC, utilizando como critérios norteadores a informação disponibilizada pela biblioteca (acervo), a ocupação dos seus espaços e os serviços prestados. A entrevista foi aplicada em vinte e duas pessoas da comunidade externa e interna da universidade, além de três empresários de organizações consideradas inovadoras da região próxima a Universidade. A coleta de dados objetivou identificar oportunidades de inovação a partir de aspectos percebidos pelos entrevistados que podem ser melhorados na biblioteca. Dentre algumas dificuldades vivenciadas pelos interagentes da biblioteca, destacaram-se os problemas relacionados a sinalização.

Finalizada a entrevista, deu-se início a etapa de análise e síntese para a geração de ideias inovadoras com o objetivo de melhorar ou minimizar os problemas de sinalização detectados. Para tanto foi empregada uma técnica denominada de grupo focal. O objetivo principal de um grupo focal é instigar os participantes a descreverem suas percepções a respeito dos tópicos em discussão e também buscar soluções para os problemas que se apresentam em suas rotinas de trabalho. $O$ grupo focal criado nesta pesquisa envolveu representantes de professores, alunos e servidores da UDESC. A dinâmica do grupo focal ocorreu da seguinte forma: a) foram criados três grupos, cada qual formado por professores, alunos e servidores; b) para os grupos foram apresentadas quatro questões acerca das dificuldades de sinalização da biblioteca; c) os grupos puderam debater cada questão e propor soluções durante cinco minutos; d) ao final de cada sessão de debate eram apresentados e anotados os resultados, além de realizar o rodízio de um integrante de cada grupo.

Concluída essa etapa, deu-se inicio ao processo de prototipação, realizada pelos orientadores da pesquisa. Nesta fase foram discutidas as alternativas para prototipar as soluções formuladas pelo grupo focal. 


\section{APLICAÇÃO DO DESIGN THINKING NA BIBLIOTECA DA UDESC}

A aplicação do processo de DesignThinking foi utilizado para desenvolver uma proposta de inovação voltada para a melhoria da sinalização da Biblioteca Universitária da Universidade do Estado de Santa Catarina UDESC. A biblioteca da UDESC foi criada em 20 de junho de 1984, pela resolução $n^{\circ}$ 001/84 do CONSEPE (Conselho de Ensino, Pesquisa e Extensão), como órgão vinculado ao Gabinete do Reitor. É composta por uma Biblioteca Central e mais sete bibliotecas setoriais. A biblioteca adota o sistema de trabalho colaborativo, em que as diretrizes e normas das bibliotecas são definidas em conjunto com todas as bibliotecas, por meio de grupos de trabalho.

A biblioteca universitária é um dos setores mais importantes das instituições de ensino superior, pois é o espaço que trata e mantém a informação que serve de suporte para o ensino e a pesquisa. Assim, as ações da biblioteca universitária são firmadas com o propósito de melhor atender a comunidade acadêmica, sendo eficiente e eficaz em seus produtos e serviços.

O universo de interagentes da biblioteca universitária é composto, em sua grande maioria, por alunos, professores, pesquisadores e, em alguns casos, a comunidade onde a universidade está inserida, por meio de seus projetos de extensão. Um dos papéis mais importantes da biblioteca universitária é suprir as necessidades de informações técnicas científicas, organizando e disseminando a informação de acordo com o perfil de seus interagentes (MACHADO, 2003). Sendo assim, os produtos e serviços das bibliotecas devem ser pensados de acordo com o perfil traçado de seus possíveis interagentes, a fim de otimizar suas experiências dentro da biblioteca.

O emprego do DesignThinking para a realização desta pesquisa envolveu os processos de imersão, análise e síntese e ideação, e a prototipação. A partir dos processos de imersão e análise e síntese, foi identificado o aspecto de sinalização como um dos principais pontos de melhorias a serem trabalhados para o melhor uso do espaço e dos serviços da biblioteca. A condução da pesquisa e de cada um dos processos do Design 
Thinking serão descritos a seguir.

\subsection{Imersão}

Sinalização consiste no ato de identificar ambientes por meio de sinais, com o intuito de regular e facilitar a mobilidade social. Para Sánchez Avillaneda (2005, tradução nossa), a sinalização deve identificar, controlar, prevenir, organizar, orientar e proporcionar a distribuição em um lugar onde a circulação das pessoas se dê de maneira mais eficaz. No caso das bibliotecas, com a sinalização, pretende-se oportunizar uma melhor utilização do espaço pelos seus interagentes, de forma acessível. Assim, a sinalização deve visar a autonomia das pessoas, seja em sua área interna ou externa.

Por meio da realização de uma imersão preliminar com aplicação de entrevistas e reenquadramento da opinião dos interagentes da biblioteca foi possível identificar os problemas relacionados a sinalização adotados pela biblioteca central da UDESC. Comitantemente analisou-se o atual sistema de sinalização adotado pela biblioteca, buscando identificar as dificuldades relatadas pelos participantes da coleta de dados. Além disso, foram realizadas pesquisas na literatura acerca do tema, com o propósito de identificar as dificuldades das bibliotecas com a sinalização de seus setores, interna ou externamente.

Quanto à sinalização externa da biblioteca central da UDESC, não foram mencionadas críticas durante a realização das entrevistas, visto que a mesma segue o padrão da instituição, onde mantêm placas sinalizadoras em diversos pontos dos campi, bem como uma placa em frente ao prédio da biblioteca, indicando a sua localização. O uso de sinalização textual é um ponto positivo, pois oferece uma interpretação única e diminui os ruídos de comunicação.

A sinalização interna da biblioteca, responsável pela orientação de seus interagentes quanto ao uso do espaço físico, bem como de acesso aos seus recursos e serviços, foi identificada como um dos aspectos a serem melhorados. Uma parcela significativa dos participantes da coleta de dados relatou ter dificuldade no acesso aos materiais devido à falta de familiaridade com a identificação adotada na sinalização. Uma sinalização interna eficaz da biblioteca é importante para garantir a autonomia dos interagentes no processo 
de busca da informação, o que torna importante a adoção de sinais adequados ao seu perfil para uma melhor oferta dos produtos e serviços da biblioteca.

\subsection{Análise e Síntese e Ideação}

Após a realização da imersão que possibilitou identificar o problema com a sinalização interna da biblioteca central da UDESC, deu-se início ao processo de análise e síntese. O grupo focal ou sessão generativa foi dividido em blocos de perguntas, onde o mediador gerava as discussões num primeiro momento de forma individual e, depois, junto ao grande grupo. O grupo focal foi formado pela comunidade acadêmica (alunos, professores, e servidores), e também membros externos. A partir dos questionamentos realizados, os participantes respondiam em cartões de insights, com uma percepção mais detalhada, os problemas identificados na sinalização de forma particular e suas sugestões para solucioná-los. Neste momento, já definido o público alvo, também se desenvolveu a etapa de ideação junto com o grupo focal.

Após a sessão do grupo focal, foram agrupados os cartões de forma a organizar a identificação do problema. Para tanto recorreu-se à técnica do diagrama de afinidades, que permitiu a organização por afinidade, similaridade e proximidade, além da construção do mapa conceitual para melhor visualização e simplificação dos dados coletados. Essas informações permitiram a definição dos critérios norteadores para a prototipação da sinalização da biblioteca central da UDESC.

As principais críticas apresentadas a sinalização da biblioteca foram relacionadas a sinalização do acervo, pois grande parte dos interagentes não tem conhecimento do sistema de classificação adotado pela biblioteca baseado no Código de Classificação Decimal de Dewey. A adoção dos códigos de classificação numérico por parte das bibliotecas justifica-se pela organização dos documentos por assuntos facilitando a localização dos documentos dentro do acervo das bibliotecas. De acordo com o entendimento dos participantes do grupo focal, a falta de familiaridade com a numeração do código e a distribuição dos assuntos, dificulta a autonomia para o uso do acervo por parte dos interagentes. Nesse sentido, o modelo atual de sinalização, adotado pela 
biblioteca por meio dos códigos de classificação numérico, está sob a ótica dos profissionais da biblioteca, permitindo uma melhor organização do acervo. Contudo, não possibilita uma visão sob um novo prisma que permita a remodelagem da atual sinalização a fim de proporcionar uma melhor experiência para o interagente.

\subsection{Prototipação}

Após a análise das sugestões levantadas pelo grupo focal, realizou-se uma prototipação de inovação incremental na sinalização da biblioteca central da UDESC, visando a melhoria dos serviços oferecidos.

Para uma melhor identificação dos interagentes, sugere-se o uso de rotas do conhecimento por meio do uso da sinalização de piso, diferenciada por cores, para encaminhar os interagentes aos setores da biblioteca.

Também, sugere-se a adoção de uma identidade gráfica e visual para os assuntos do acervo, com o uso de cores e figuras relativas aos assuntos, juntamente com a sinalização numérica da Classificação Decimal de Dewey já adotada pela biblioteca, para que os interagentes possam identificar os assuntos do acervo sem a necessidade de conhecimento prévio sobre o código numérico.

Juntamente a identidade visual das estantes, sugere-se a inclusão das fotos das capas de livros ao catálogo virtual, facilitando a identificação do interagente quanto à procura do livro nas estantes.

Por fim, sugere-se a adoção de mapas com o layout da biblioteca, espalhados por todos os andares, identificando sua estrutura física e a divisão e disposição do acervo pelo prédio da biblioteca, como também o uso de QRCode para identificação das estantes do acervo.

Essas sugestões, levantadas pelo grupo focal e pelos autores, buscam solucionar de forma inovadora as oportunidades de melhorias apontadas pelos interagentes quanto à sinalização utilizada pela biblioteca central da UDESC. 


\section{RESULTADOS}

O processo de Design Thinking permitiu de maneira sistematizada desenvolver uma inovação incremental, aparentemente simples, que deverá, uma vez empregada, gerar benefícios significativos para os interagentes da Biblioteca da UDESC. Neste sentido destaca-se que o valor da inovação não está relacionada com a sua complexidade ou demanda de recursos para a sua implementação, mas sim ao valor percebido por aqueles que usufruem dos resultados do processo inovativo.

Deve-se destacar que a utilização das técnicas de grupo focal, combinada com a de cartões de insights e diagrama de afinidades, foram fundamentais para que as etapas de Análise e Síntese e Ideação pudessem ter sido realizadas com sucesso, indicando soluções eficientes para o problema de sinalização interna da biblioteca.

Outro aspecto importante constatado com o desenvolvimento desta pesquisa é que a inovação pode ser aplicada em qualquer contexto organizacional, independente do seu tamanho, tipo (comercial, industrial ou de serviços), e ramo de atuação. Inovar nas bibliotecas é possível e necessário, e para que possa acontecer é fundamental que os atores envolvidos no processo estejam libertos de paradigmas e ideias preconcebidas.

Finalmente, ressalta-se que esta experiência de pesquisa voltada para o desenvolvimento de uma inovação suscita refletir sobre a necessidade das bibliotecas adotarem um modelo de gestão da inovação, de modo sistematizar o processo inovativo, tornando-o cíclico, frequente e permanente nas unidades de informação.

\section{CONCLUSÃO}

A prática da inovação tornou-se a chave de sucesso para a sustentabilidade e prosperidade das organizações. Inovar não é uma tarefa tão simples assim: exige ações sistematizadas e um ambiente que permita e estimule a geração de ideias e a criatividade, ou seja, é preciso criar e manter a cultura da inovação. 
Uma biblioteca universitária é uma organização, portanto precisa mirar na inovação, especialmente num momento em que as mudanças tecnológicas são tão intensas e constantes que alteram as demandas e expectativas daqueles que usam os produtos e serviços das bibliotecas.

Para que a inovação aconteça é necessário o emprego de práticas e técnicas que facilitem o seu desenvolvimento. A aplicação dos processos de Design Thinking como estratégia de inovação é bastante recente no ambiente corporativo, pois sua forma de raciocínio para a geração de ideias e soluções para problemas complexos extrapola os modelos convencionais. Entretanto, os resultados advindos da aplicação do Design Thinking são promissores sob o ponto de vista do processo de inovação, por utilizar diversas técnicas que permitem um trabalho colaborativo e com foco na solução.

Para de fato compreender efetivamente o processo de inovação, que é complexo, foi necessário aprender a inovar. Por isso, este trabalho teve como principal resultado o entendimento, na prática, do conceito de inovação por meio da aplicação do processo de Design Thinking. Pode-se perceber a importância de todas as etapas do Design Thinking, desde as pesquisas preliminares até o momento de geração das ideias e a prototipação do serviço. De fato inovar requer disciplina por parte da equipe do projeto, mas ao mesmo tempo um ambiente flexível que permita a criatividade.

\section{REFERÊNCIAS}

ARAÚJO, Leonardo; GAVA, Rogério. Empresas proativas: como antecipar mudanças no mercado. Rio de Janeiro: Campus, 2011.

BIOLCHINI, Clarissa; PIMENTA, Marcelo; OROFINO, Maria Augusta.

Ferramentas visuais para estrategistas. São Paulo: Bmgenbrasil, 2012. Disponível em: <http://materiais.bmgenbrasil.com/estrategista-visual >. Acesso em: 15 dez. 2015.

BROWN, Tim. Design thinking: uma metodologia poderosa para decretar o fim das velhas ideias. Rio de Janeiro: Campus, 2010.

CHRISTENSEN, Clayton. The innovator's dilemma. Nova York: Harper Business Essentials, 2003. 
CORAL, Eliza; OGLIARI, André; ABREU, Aline França. Gestão integrada da inovação: estratégia, organização e desenvolvimento de produtos. São Paulo: Atlas, 2008.

DESCHAMPS, Fernando; HERMANN, Ingo Louis. Gestão da inovação. Florianópolis: SENAI/SC, 2011.

FINEP - FINANCIADORA DE ESTUDOS E PROJETOS. Brasil inovador: o desafio empreendedor - 40 histórias de sucesso de empresas que investem em inovação. Brasília: IEL, 2006.

FREEMAN, Christopher; PEREZ, Carlota. Structural crises of adjustment, business cycles and investment Behaviour. In: DOSI, Giovanni et al. Technical change and economic theory. London New York: Pinter Publishers, 1988. p. $38-66$

GIBSON, Rowan; SKARZYNSKI, Peter. Inovação prioridade N.1: o caminho para trasformações nas organizações. Rio de Janeiro: Elsevier, 2008.

JUNGMANN, Diana de Mello; BONETTI, Esther Aquemi. Proteção da criatividade e inovação: entendendo a propriedade intelectual: guia para jornalistas. Brasília: IEL, 2010.

MACHADO, Murilo Milton. Mapeamento espacial e proposta de sinalização no serviço de periódicos da Biblioteca Central da UFSC. Revista ACB:

Biblioteconomia em Santa Catarina, Florianópolis, v. 8, n. 1, p. 70-78, 2003.

MARTIN, Roger. Design thinking: achieving insights via the knowledge funnel. Strategy \& Leadership, United Kingdom, v. 38, n. 2, p. 37-41, 2010.

\section{OCDE - ORGANIZAÇÃO PARA COOPERAÇÃO ECONÔMICA E} DESENVOLVIMENTO. Manual de Oslo: proposta de diretrizes para coleta e interpretação de dados sobre inovação tecnológica. Brasília: FINEP, 2005.

OROFINO, Maria Augusta Rodrigues. Técnicas de criação do conhecimento no desenvolvimento de modelos de negócio. 2011. 223 f. Dissertação (Mestrado em Engenharia e Gestão do Conhecimento) - Universidade Federal de Santa Catarina, Centro Tecnológico, Florianópolis. 2011.

SÁNCHEZ AVILLANEDA, María del Rocío. Señalética: conceptos y fundamentos: una aplicacion em bibliotecas. Buenos Aires: Alfagrama, 2005.

SCHUMPETER, Joseph Alois. Teoria do desenvolvimento econômico: uma investigação sobre lucros, capital credito, juro e o ciclo econômico. São Paulo: Nova cultural, 1997.

TERRA, José Claudi Cyrineu. Inovação: quebrando paradigmas para vencer. São Paulo: Saraiva, 2007. 
THIOLLENT, Michel. Pesquisa-ação nas organizações. São Paulo: Atlas, 1997.

TIDD, Joe; BESSANT, John; PAVITT, Keith. Gestão da inovação. 3. ed. Porto Alegre: Bookman, 2008.

VIANNA, Mauricio et al. Design thinking: inovação em negócios. 5. ed. Rio de Janeiro: MJV Press, 2014.

Title

Design thinking as an innovation strategy in libraries

\begin{abstract}
Introduction: The need to innovate and characterize what is new, makes innovation a permanently term on the agenda of a growing number of organizations in various segments. Libraries as organizations need to innovate it is an emerging.

Objective: To use the techniques and processes of design thinking as an instrument of innovation in the University Library of UDESC.

Methodology: This is a qualitative research, developed through an action research. Data were collected through interviews. Once the data collection carried out the steps of the DT from the application of the focus group technique.

Results: The process of DT allowed to develop an incremental innovation to the Library. For innovation to happen it is essential that the actors involved in the process are freed paradigms and preconceived ideas. The use of focus group techniques, combined with the insight cards and affinity diagram were fundamental to the steps of the DT could have been carried out successfully.

Conclusions: The prototype of innovation in Library of UDESC suggested a significant improvement to the use of its structure and available resources. The DT proved to be simple and effective to systematize innovation in libraries.
\end{abstract}

Keywords: Innovation. University libraries.

\title{
Titulo
}

Design thinking como estrategia de innovación en las bibliotecas

Resumen

Introducción: La necesidad de innovar y caracterizar lo que es nuevo, hace que la innovación un término de forma permanente en la agenda de un número creciente de organizaciones en varios segmentos. Las bibliotecas como organizaciones necesitan innovar es una emergente.

Objetivo: Para utilizar las técnicas y los procesos de pensamiento de diseño como instrumento de innovación en la Biblioteca de la Universidad de UDESC.

Metodología: Se trata de una investigación cualitativa, desarrollado a través de una investigación-acción. Los datos fueron recolectados a través de entrevistas. Una vez 
Jordan Paulesky Juliani, Diego de Castro Vieira, Déborah Medeiros, Douglas Paulesky Juliani.

Design thinking como estratégia de inovação em bibliotecas

que la recolección de datos lleva a cabo los pasos de la DT de la aplicación de la técnica de grupo focal.

Resultados: El proceso de DT permitió desarrollar una innovación incremental de la Biblioteca. Para que la innovación suceda, es esencial que los actores involucrados en el proceso son paradigmas e ideas preconcebidas liberados. El uso de técnicas de grupos focales, combinado con el diagrama de tarjetas de intuición y de afinidad eran fundamentales para las etapas de la DT se podría haber llevado a cabo con éxito. Conclusiones: El prototipo de la innovación en la Biblioteca del UDESC sugirieron una mejora significativa en el uso de su estructura y los recursos disponibles. EI DT resultó ser simple y eficaz para sistematizar la innovación en las bibliotecas.

Palabras claves: La innovación. Las bibliotecas universitarias.

Recebido em: 10.04.2016

Aceito em: 18.11.2016 